\title{
The Cultivation of Critical Thinking in the Teaching of College English Reading
}

\author{
Yuanzhen $\mathrm{Wu}$ \\ Nanchang University Gongqing College \\ Gongqingcheng, China
}

\author{
Shijun Liu \\ Nanchang University Gongqing College \\ Gongqingcheng, China
}

\begin{abstract}
Since twenty years ago, scholars in foreign language teaching have pointed out that lack of critical thinking has hindered the cultivation of comprehensive abilities of English majors. Yet few previous researches focus on the application of critical thinking in actual teaching. The paper tries to explore the effectiveness of the teaching in the reading course by questionoriented and task-oriented measures in different stages to cultivate this capacity of critical thinking.
\end{abstract}

Keywords-critical thinking; reading teaching; question; task

\section{INTRODUCTION}

It should be noted that philosophical bases are deeply rooted in thinking, which can be revealed in the famous saying by Heidegger, that is, all the tasks of philosophy are to inspire thinking; according to Socrates, education is not instilling, but igniting the flames. And I think therefore I am by Descartes also highlights the significant role of thinking as well.

In foreign language teaching, much emphasis has been laid on the five basic skills of listening, speaking, reading, writing and translating for a long time. Professor Huang Yuanshen pointed out just twenty years ago that students majoring in foreign languages are prone to be lack of the ability of independent thinking, which is in a large measure due to the neglecting of the cultivation of the thinking ability of language learners during the teaching of five basic skills.

Other experts and scholars in foreign language teaching have expressed similar concern about the thinking ability of foreign language majors. They also realized that foreign language graduates have a poor humanistic foundation and a weak critical thinking ability. They have conducted in-depth and meticulous exploration to their thinking ability, and also drawn some alarming conclusions: foreign language students suffer from what is called "thinking absentism", that is, lack of speculative ability. Compared with other liberal arts majors, foreign language graduates show poor thinking ability and lack of intelligence, and so on.

Based on the above background, it is in urgent need to explore the countermeasures to tackle such issues and this paper aims to mainly focus on the cultivation of critical thinking in college English reading class.

\section{Key Notions OF CRITICAL THINKING}

According Facione (2006), critical thinking is defined as a purposeful process of self-regulation and judgment on the correctness of the process, theory, method, background, evidence, and criteria for evaluating knowledge.

Richard (2003) points out that critical reading is a highlevel understanding of the text. It includes the skills of interpretation and evaluation, which allows the reader to distinguish between important and non-essential information, tell facts from opinions, and determine the author's purpose and attitude. At the same time, it is necessary to derive the meaning of the words through reasoning and then fill in the empty parts of the information to get a logical conclusion.

In some cases we read just for pleasure or to obtain information, taking it for granted that the information contained is reliable and that is why critical thinking is required. Critical thinking involves taking an attitude of reflective skepticism towards what we read and what people tell us. Reflective indicates thinking seriously about what we have read or heard; skepticism suggests not taking it for granted that what's read or heard is true or correct while it is of necessity to try to evaluate or assess the validity of the information and opinions encountered. However, it is worth noting that in this context critical does not just mean looking for mistakes or weaknesses of a passage or a book, even the author. Instead it means analyzing, evaluating what we read and judging what is good or bad and what is not in the reading, and make reflections.

To read critically is to make judgments about how a text is argued. This is a highly reflective skill requiring to stand back and gain some distance from the text one is reading. Try not to read only or primarily for information; instead read looking for ways of thinking about the subject matter.

In short, critical reading means reading - and thinking with an open mind, not to agree or disagree, but to discover ideas and information. To be a critical reader doesn't mean criticizing. In essence, everything is up for question. Readers are to be more concerned with finding the truth than being right and have good reasons for believing some things and disbelieving others, for agreeing with some authors and disagreeing with others. The goal of critical thinking is to evaluate information in an unbiased way. This includes being open to changing your mind about a subject if the good evidence exists. However, you should also try not to be 
influenced by unsound evidence. For instance, when you read a piece of fiction critically, use your common sense to determine what the writer means, as opposed to what the written words actually indicate. One way to read a novel critically is to be aware of the lessons or messages that a writer is sending in a subtle way.

\section{Cultivating CRiticAl Thinking IN READING TEACHING}

The traditional way of reading class focuses on the input of grammar and explanation of words, phrases and grammar and ignore the logical connections between sentences and paragraphs, leading to the failure of the understanding of the whole passage, let alone the evaluation of passages, e.g. the writer's writing style, purpose and attitude. Yet critical reading does not deny the teaching of these aspects for the deeper interpretation of a passage is based on the exact understanding of sentences and paragraphs. In essence, reading involves basic overall comprehension of a passage as well as thinking, judging and evaluation. And in this paper, two major approaches, question-oriented and task-oriented, are employed in different periods of reading teaching, that is, before class, in class and after class.

The priority in critical reading lies in questions which should be put forward first, then analyzed and settled eventually. Yang (2015) studies the cognitive features of reading classroom questioning and critical thinking development according to Bloom's taxonomy, based on which cognitive levels of questions are identified. The first level is concerning knowledge, with such questions as what's the meaning of the word? And this is what traditional reading classroom focuses on. The second involves comprehension, including questions like what's the main idea of the passage and how do you paraphrase the sentence? Next is on application, e.g. could you express the idea in your own words? The fourth is analysis, consisting of questions like what are facts and opinions and what's the writer's purpose? The last two are synthesis and evaluation, respectively concerning creating original views based on old knowledge and making judgments. Common questions of these can be presented like could you give some advice in solving the problem and what's the writing style of the passage? Among this classification, the last four constitute the core of critical reading in this paper, that is application, analysis, synthesis and evaluation.

\section{A. Before Class}

Teachers are required to assign preview homework to search background information related to the content of an article, in order to stir up students' interest and curiosity in reading. Take an article entitled You Call This a Mugging? for instance. It is about the experience of a little girl totally alone in a quiet park, who was reading her English book for the next day. Before this class, students are assigned to look for the brief introduction of Beowulf, which is mentioned several times in this article, both in English and Chinese. The second task is predicting what will be included in the passage just according to the title and the answer to the question, namely the title. The questions related to the two tasks can be presented as:
- What is Beowulf about?

- Can you call it a mugging? Yes or no? why?

The latter involves the reading skill of predicting, especially about the topic of the text. The purpose of practicing it is to activate relevant background knowledge, helping students' mind to be prepared for the new information and thus they can understand the content of the text better.

\section{B. In Class}

The homework in the last section involves the first two levels of Bloom's taxonomy, namely, knowledge and comprehension. In class, the first task is that students work in pairs and compare the background information of Beowulf searched. It turns out students pay attention to different aspects of this book, some on the characters, but most on the plot. However, although lots of information has been collected, there are several students who do not even know the meaning of the name of the book, which indicates no clear understanding of that information.

Furthermore, after predicting the answer to the title, it is time for students to check whether they have made correct predictions. As has been mentioned, the significance of the reading skill of predicting lies in stimulating previous experiences, and concerning this title of the article, students should pay much attention to not only the unfamiliar word mugging, but also its form, that is, a question. This can recall their experience in reading I have a dream by Martin Luther King, which also consists of a question When will you be satisfied, a rhetorical question, to be exact. Therefore, the focus is on guiding students to find the answer to the question, and based on previous reading experience, apparently it contains a negative answer itself. According to this analysis, it becomes less difficult to lead students to make further predictions:

- Who would be the mugger and why did he commit such a mugging?

- What would happen to her? Do you think she would be safe?

As it progresses, the most interesting part is that students check their predictions and while doing this, it keeps them concentrated on reading and gradually enhance reading comprehension. It follows that in class the third and fourth level can be indicated in this stage of teaching, namely application and analysis.

\section{After Class}

Questions for discussion after class are assigned among groups members concerning synthesis and evaluation:

- What would you do if you met a mugger in a quiet place?

- Is it difficult to find a quiet place for you to read on your campus? If it is, how do you solve the problem?

In addition, it is worth mentioning that this article features detailed description of emotions and actions and thus it is essential to check whether they really understand these 
expressions. Examples can be listed as follows: scared excitement started welling up inside of me; my eyes bulged open in panic; the words never came to my lips and such vivid verbs as sniff, grab, and sneer, hurl and so on. Therefore, the other task for students to finish after class is the role play. Students work in pairs and one act as the girl, the other the mugger. In this way, students are familiar with not only the plot of the story but also the correct understanding of different emotions and actions if they can perform well rather than simply doing translation work. And the next class begins with performance of several groups, followed by comments, including suggestions of other groups. Feedback is to be given by the teacher as well based on their presentation.

\section{CONCLUSION}

As is revealed from above, by analyzing the whole process of an English reading class, it can be found that critical thinking needs to be applied to the teaching to ensure their concentration in class and cooperative learning after class, and that is what we call critical reading, which requires comprehending, questioning, doubting and evaluating. And it involves question-oriented and task-oriented approaches that teachers could adopt to stimulate critical thinking of students while reading.

\section{REFERENCES}

[1] Facione, P.A. Critical Thinking: What it is and Why it counts [M]. California Academic Press, 2006.

[2] Richard Pirozzi: Critical Reading, Critical Thinking: A Contemporary Issues Approach[M]. New York: Addison-Wesley Education Publishers Inc. 2003.

[3] Yang Lifang, The Cognitive Features of Reading Classroom Questioning and Critical Thinking Development, Foreign Languages in China, vol. 2, pp. 68-79, 2015. 